\title{
Regulation of Epithelial-to-Mesenchymal Transition Using Biomimetic Fibrous Scaffolds
}

\author{
Anitha Ravikrishnan ${ }^{1, \$}$, Tugba Ozdemir ${ }^{1, \$}$, Mohamed Bah ${ }^{1}$, Karen A. Baskerville ${ }^{2}$, S. Ismat \\ Shah $^{1,3}$, Ayyappan K. Rajasekaran ${ }^{1,4,5}$, and Xinqiao Jia ${ }^{1,4,6, *}$ \\ ${ }^{1}$ Department of Materials Science and Engineering, University of Delaware, Newark, DE 19716, \\ USA \\ ${ }^{2}$ Department of Biology, Lincoln University, Lincoln University, PA 19352, USA \\ ${ }^{3}$ Department of Physics and Astronomy, University of Delaware, Newark, DE 19716, USA \\ ${ }^{4}$ Department of Biological Sciences, University of Delaware, Newark, DE, 19716, USA \\ ${ }^{5}$ Therapy Architects, LLC, Helen F Graham Cancer Center, Newark, DE, 19718, USA \\ ${ }^{6}$ Department of Biomedical Engineering, University of Delaware, Newark, DE 19716, USA
}

\begin{abstract}
Epithelial-to-mesenchymal transition (EMT) is a well-studied biological process that takes place during embryogenesis, carcinogenesis and tissue fibrosis. During EMT, the polarized epithelial cells with a cuboidal architecture adopt an elongated fibroblast-like morphology. This process is accompanied by the expression of many EMT-specific molecular markers. While the molecular mechanism leading to EMT has been well established, the effects of matrix topography and microstructure have not been clearly elucidated. Synthetic scaffolds mimicking the mesh-like structure of the basement membrane with an average fiber diameter of $0.5 \mu \mathrm{m}$ and $5 \mu \mathrm{m}$ were produced via electrospinning of poly( $\varepsilon$-caprolactone) (PCL) and were used to test the significance of fiber diameter on EMT. Cell-adhesive peptide motifs were conjugated to the fiber surface to facilitate cell attachment. Madin-Darby Canine Kidney (MDCK) cells grown on these substrates showed distinct phenotypes. On $0.5 \mu \mathrm{m}$ substrates, cells grew as compact colonies with an epithelial phenotype. On $5 \mu \mathrm{m}$ scaffolds, cells were more individually dispersed and appeared more fibroblastic. Upon addition of hepatocyte growth factor (HGF), an EMT inducer, cells grown on the $0.5 \mu \mathrm{m}$ scaffold underwent pronounced scattering, as evidenced by the alteration of cell morphology, localization of focal adhesion complex, weakening of cell-cell adhesion, and upregulation of mesenchymal markers. By contrast, HGF did not induce a pronounced scattering of MDCK cells cultured on the $5.0 \mu \mathrm{m}$ scaffold. Collectively, our results show that the alteration of the fiber diameter of proteins found in the basement membrane may create enough disturbances in
\end{abstract}

\footnotetext{
*To whom correspondence should be addressed: Xinqiao Jia, 201 DuPont Hall, Department of Materials Science and Engineering, University of Delaware, Newark, DE, 19716, USA. Phone: 302-831-6553, Fax: 302-831-4545, xjia@udel.edu.

$\$$ These two authors contributed equally to this work.

Supporting information: Peptide synthesis and characterization, Ninhydrin assay on scaffolds subjected to aminolysis treatment, confocal images showing the development of F-actin stress fibers, and cell proliferation analyzed by Presto Blue assay. This material is available free of charge via the Internet at http://pubs.acs.org.
} 
epithelial organization and scattering that might have important implications in disease progression.

\section{Keywords}

Fibrous Scaffolds; MDCK Cells; Fiber Diameter; Hepatocyte Growth Factor; Epithelial-toMesenchymal Transition; Phenotype

\section{Introduction}

Epithelial to mesenchymal transition (EMT) is a complex biological process that takes place during tissue development and disease progression. During development, successive EMT events generate embryonic organs and tissues. In healthy adult epithelial tissues, polarized epithelial cells bonded to the basement membrane are held together through adherens junction complexes, consisting of F-actin, catenins and E-cadherin. ${ }^{1-3}$ Under pathological conditions, in response to EMT-inducing signals, the epithelial cells weaken their cell-cell adhesions and lose the apico-basal polarity as the EMT inducers suppress the genes encoding proteins involved in both adherens junctions and cell polarity. ${ }^{2,4}$ During EMT, cells also undergo cytoskeletal reorganization, ${ }^{5-6}$ adopt a more elongated cell morphology and become progressively more migratory and invasive. ${ }^{7-8}$ In chronic fibrosis, the transformed cells undergo abnormal remodeling of their extracellular matrix (ECM) and produce excessive proteins and proteoglycans, ${ }^{9}$ resulting in the thickening and scarring of the tissue. At the onset of carcinoma invasion, epithelial cells are released from the cell clusters into neighboring tissues with varying tissue structures, mechanical properties and dimensionality, spreading cancer to a distal organ.

The basement membrane/extracellular matrix (ECM) composed mainly of fibrillar proteins, such as collagen and fibronectin, and amorphous fillers, such as glycosaminoglycans, provides structural support and contextual information to the resident cells, serving as a key regulator of cell functions. During EMT, the ECM undergoes drastic compositional, structural and mechanical changes to accommodate aberrant tissue growth. ${ }^{10-12}$ The ECM reorganization ${ }^{13-15}$ is associated with the alteration in the density and orientation of fibrillar proteins. ${ }^{16}$ The increase or decrease in fiber crosslinking not only affects the matrix stiffness but also alters the ligand density, thereby influencing cell migration. ${ }^{17}$ During cancer metastasis, the interstitial matrix is remodeled by the stromal cells to generate invasive pathways for cancer cell migration. ${ }^{18}$ By contrast, increased deposition of fibrillar proteins prevents the normal wound healing process and results in tissue fibrosis ${ }^{19-20}$.

Paracrine effectors are potent inducers of EMT. Particularly, hepatocyte growth factor (HGF), a fibroblast-derived protein known as the scatter factor, affects the intercellular connections and mobility of normal epithelial cells, and thus might be involved in embryogenesis or wound healing. ${ }^{21}$ Madin-Darby canine kidney (MDCK) epithelial cells grown in collagen gels in the presence of exogenous HGF form branching tubules, whereas cells grown in control gels without HGF or in fibroblast conditioned media with HGF antibody only develop into spherical cysts. ${ }^{22}$ It is known that HGF binds a tyrosine kinase receptor c-Met proto-oncogene with high affinity to induce epithelial morphogenesis. ${ }^{23}$ Of 
note, the morphogenetic effects of HGF are dependent not only on the target cell type but also the environmental context and culture conditions. Although a large body of literature ${ }^{24-26}$ reports the HGF-induced scattering or tubulogenesis by culturing MDCK cells on planar substrates or in collagen gels or Matrigel, the roles of the ECM topography on the initial clustering and HGF-induced scattering have not been elucidated.

To gain a fundamental understanding on how physical features of the ECM define cellular behaviors and alter cell phenotypes, a straightforward and reliable method for producing biomimetic fibrous scaffolds with controlled diameter and surface chemistry is needed. Electrospinning is a powerful technique for the fabrication of synthetic scaffolds that closely mimic the structure, morphology and mechanical properties of the natural ECM. ${ }^{27-29}$ These micro/nano fibrous scaffolds, with the interconnected porous network and high surface to volume ratio, provide a favorable environment for cell attachment, migration and proliferation. ${ }^{30-32}$ Owing to its biocompatibility, high molecular weight and semi-crystalline nature, poly( $\varepsilon$-caprolactone) (PCL) ${ }^{33}$ has been electrospun into fibrous scaffolds for various tissue engineering applications. ${ }^{34-36}$ Various surface modification methods have been applied to the PCL fibers to improve the hydrophilicity and to promote cell-scaffold interactions without compromising the bulk properties. ${ }^{37-39}$ In the current investigation, we assessed the ability of electrospun PCL scaffolds with varying fiber diameters to support the attachment, growth and differentiation of MDCK cells. Because integrin signaling is important in EMT, the amino acid sequence corresponding to integrin binding receptors at focal adhesion complexes ${ }^{40-41}$ was conjugated to the PCL scaffold. We further evaluated how the fiber diameter affects the HGF-induced cell scattering on the scaffold. Our results highlight the importance of the biophysical attributes of the cellular microenvironment on the fundamental aspects of EMT in tissue morphogenesis and wound healing.

\section{Materials and Methods}

\subsection{Chemicals and reagents}

Poly ( $\varepsilon$-caprolactone) (PCL, $\sim 80 \mathrm{kDa}$ ), hexamethylenediamine (HMD) and ethylenediaminetetraacetic acid (EDTA.4Na) were purchased from Sigma-Aldrich (St. Louis, MO). Organic solvents, including chloroform, N, N-dimethyl formamide (DMF), methylene chloride, dichloromethane (DCM) and isopropanol, as well as the difunctional crosslinker, sulfosuccinimidyl 4-(N-maleimidomethyl) cyclohexane-1-carboxylate (sulfo-SMCC), were obtained from Thermo-Fisher (Rockford, IL) and were used without further purification. Deionized water ( $\mathrm{DI} \mathrm{H}_{2} \mathrm{O}$ ) was sourced from a NANOpure Diamond water purification system (Thermo Scientific, Barnstead, NH). Phosphate buffered saline (PBS) was purchased from Gibco (Life Technologies Carlsbad, CA). Monoclonal anti-vinculin antibody was purchased from Sigma-Aldrich (St. Louis, MO), monoclonal mouse anti-vimentin antibody was purchased from GenWay Biotech, Inc., (San Diego, CA) and purified mouse anti-Ecadherin antibody was purchased from BD Biosciences (San Diego, CA). Alexa 488, Alexa 647 and Alexa 488-conjugated goat anti-mouse or rabbit IgG, as well as Alexa 568conjugated Phalloidin, were purchased from Molecular Probes (Eugene, OR). Recombinant human hepatocyte growth factor (HGF), DAPI, Syto 13 and propidium iodide (PI) were 
obtained from Invitrogen (Grand Island, NY). CellTracker ${ }^{\mathrm{TM}}$ red was purchased from Life Technologies (Carlsbad, CA).

\subsection{Scaffold fabrication and modification}

2.2.1. Scaffold fabrication-Fibrous PCL scaffolds with varying fiber diameter were fabricated using different solvents and electrospinning parameters. To produce a nonwoven mat of uniform submicron fibers, PCL was dissolved in DCM/DMF (7:3, v/v) at a concentration of $12 \mathrm{wt} \%$. The solution was transferred to a $3 \mathrm{~mL}$ syringe capped with a $21 \mathrm{G}$ blunt ended needle (Becton Dickinson, Franklin Lakes, NJ). The syringe was suspended horizontally adjacent to a grounded aluminum collector plate at a fixed distance of $21 \mathrm{~cm}$ and a power supply was wired to the metal needle with an alligator clip to establish a constant electric potential of $12 \mathrm{kV}$. The PCL solution was spun at a flow rate of $1 \mathrm{~mL} / \mathrm{h}$ using an automatic syringe pump (New Era Pump Systems, Farmingdale, NY). To produce micron-sized fibers, a $15 \mathrm{wt} \% \mathrm{PCL} /$ chloroform solution was spun from a $16 \mathrm{G}$ needle at a flow rate of $1.5 \mathrm{~mL} / \mathrm{h}$ with a needle-to-collector distance of $16 \mathrm{~cm}$. The collected fiber mats, with an average thickness of $130 \mu \mathrm{m}$, were dried overnight under vacuum.

2.2.2. Surface functionalization-A cell-adhesive peptide with a sequence of CGGWGRGDSPG (RGD-SH) was prepared on a PS3 peptide synthesizer (Protein Technologies Tucson, AZ) using the Rink Amide resin (EMD Millipore, Billerica, MA) following standard Fmoc solid phase peptide synthesis protocols, with the $N$-terminus was acetylated and the $\mathrm{C}$-terminus amidated. ${ }^{42-44}$ The crude peptide was purified using the Waters HPLC equipped with a Phenomenex ${ }^{\circledR} \mathrm{C} 18$ preparative column and lyophilized to obtain dry powder. The HPLC traces of the purified peptide are shown in Fig. S1. The molecular weight of the purified peptide was analyzed by electrospray ionization mass spectrometry (ESI-MS, Fig. S2) (Thermo LCQ LC-MS system with ion trap mass analyzer, San Jose, CA). ESI-MS m/z ([M+H] $\left.]^{+}\right): 1089.0$ (calculated), 1089.7 (found).

PCL scaffolds were cut into circular disks of $10 \mathrm{~mm}$ diameter using an Acuderm punch (Fort Lauderdale, FL). Individual disks were immersed in an ethanol/water mixture $(1 / 1, \mathrm{v} / \mathrm{v})$ under gentle shaking for $2 \mathrm{~h}$ to remove any residual contaminants. Scaffolds were then allowed to react with hexamethylenediamine (HMD) in 2-propanol (10 wt\%) at ambient temperature for $24 \mathrm{~h},{ }^{45}$ and unreacted HMD was removed by a thorough wash with $\mathrm{DI}_{2} \mathrm{H}_{2} \mathrm{O}$. The HMD-treated scaffolds were then washed with PBS $(0.1 \mathrm{M})$ containing $0.15 \mathrm{M} \mathrm{NaCl}$ at pH 7.2 three times ( 5 min each). Next, the scaffolds were incubated with a sulfo-SMCC solution ( $4 \mathrm{mg} / \mathrm{mL}$ in PBS, $\mathrm{pH} 7.4)$ at room temperature for $1 \mathrm{~h}$. The sulfo-SMCC-treated scaffolds were washed three times with a PBS buffer containing 0.1 M EDTA at pH 7.0. Finally, the scaffold was incubated with RGD-SH at $0.2 \mathrm{mg} / \mathrm{mL}$ in PBS at $4{ }^{\circ} \mathrm{C}$ overnight to immobilize the cell adhesive peptide. ${ }^{46}$ Scaffolds were washed thoroughly with PBS to remove excess unbound peptides and dried under vacuum.

\subsection{Scaffold characterization}

2.3.1. Scanning electron microscopy (SEM)—Scaffold morphology was characterized using a Hitachi S4700 Scanning Electron Microscope. Samples were mounted on aluminum stubs using carbon tape and were sputter coated with platinum using Leica EM 
ACE600. The average diameter and pore size of the fibrous scaffolds were analyzed using DiameterJ, ${ }^{47}$ and Image ${ }^{48}$ software, respectively.

2.3.2. Contact angle analysis-For contact angle analysis, spun-cast films were used in place of the fibrous mats to eliminate topography related complications in data analysis and to unambiguously confirm the changes of surface chemistry. Specifically, PCL was spun cast from a $5 \mathrm{wt} \%$ chloroform solution onto a silicon wafer with a $300 \mathrm{~nm}$-thick oxide layer, freshly clean using a Piranha solution. The as-spun films were annealed at $60^{\circ} \mathrm{C}$ for $1 \mathrm{~h}$. The silicon wafer supported PCL film ( $3.6 \mu \mathrm{m}$ thick, as determined by profilometry) was subjected to the same surface modifications described above for PCL fibers. Water contact angle was measured at room temperature using the sessile drop method on a Ramé-Hart contact angle Goniometer (Succasunna, NJ). A distilled water droplet was placed on five different regions of the test substrates and the measured angles were averaged.

2.3.3. X-ray photoelectron spectroscopy (XPS)—X-ray photoelectron spectroscopic (XPS) spectra of the spun-cast films, before and after various steps of surface modification, were recorded using Surface Science Instruments Model 301 ESCA with monochromatic Al $\mathrm{Ka}$ and $\mathrm{Mg} \mathrm{Ka} \mathrm{X}$-rays dual source, with a resolution of $0.4 \mathrm{eV}$. The $\mathrm{C} 1 \mathrm{~s}$ standard at 284.6 $\mathrm{eV}$ was used for the correction of the obtained spectra, in order to account for peak shifting due to charging. Data reported represents the chemical composition of the surface of the polymer film at a sampling depth of 3 to $10 \mathrm{~nm}$, depending on the intensity of the emitted electron. The $\mathrm{x}$-ray source is located perpendicular to the analyzer, while the sample is located $50^{\circ}$ from the analyzer.

\subsubsection{Fourier transform infrared spectroscopy (FT-IR)—A Fourier Transform} Infrared Spectrometer (Nexus 670 FT-IR, Thermo Nicolet, Waltham, MA) was used to confirm the aminolysis on the surface of PCL films. Spun-cast films, before and after surface modification, were analyzed. The absorption spectra at the mid-infrared region (500 to 4000 wavenumbers) were recorded.

2.3.5. Confocal microscopy-The as-spun fibers and the peptide modified fibers were imaged using an LSM880 Multiphoton Confocal Microscope (Zeiss). For confocal imaging of the as-spun scaffolds, the collected fibers were immersed in a PBS solution of CellTracker ${ }^{\mathrm{TM}} \operatorname{Red}(1: 1000)$ for $30 \mathrm{~min}$. Separately, a multi-photon confocal microscope, operated at 30\% laser power, was used to confirm the peptide conjugation on PCL scaffolds based on tryptophan fluorescence. Briefly, virgin PCL scaffolds, RGD-conjugated PCL scaffolds and RGD-coated clean glass slides were imaged separately in order to get sample specific fluorescence emission spectra. All samples were excited at $280 \mathrm{~nm}$ with an argon laser source and the unfiltered emission spectra were collected. The fluorescence signal associated with tryptophan residue on RGD-modified PCL scaffolds was obtained by subtracting the background fluorescence from PCL.

\subsection{Cell culture}

Madin-Darby canine kidney (MDCK) NBL2 cells (ATCC, Manassas, VA) were cultured in Eagle's minimum essential medium (EMEM) (ATCC, Manassas, VA) supplemented with 
$10 \%$ fetal bovine serum (FBS) and $100 \mathrm{IU} / \mathrm{mL}$ penicillin/streptomycin in a humidified $37^{\circ} \mathrm{C}$ incubator maintained at $5 \% \mathrm{CO}_{2}$ and $95 \%$ air. Cell culture media was changed every other day, and cells were routinely passaged using $0.25 \%$ (w/v) trypsin containing $0.02 \%$ EDTA. Prior to cell culture, the fibrous scaffolds were gently agitated in $70 \%$ ethanol overnight. After washing with fresh, serum free media, the scaffolds were exposed to germicidal UV light for $15 \mathrm{~min}$, followed by a 3-h equilibration in cell culture media. MDCK cells were plated on the scaffold at a seeding density of 10,000 cells/scaffold and were incubated in media containing $0.5 \%$ FBS for $2 \mathrm{~h}$. Subsequently, the low serum media was replaced by EMEM containing 10\% FBS. After 36-h incubation, the media was supplemented with HGF $(50 \mathrm{ng} / \mathrm{mL})$ and cells were cultured for an additional $12 \mathrm{~h}$ before individual constructs were collected and processed for immunostaining and confocal imaging.

\subsection{Biological characterization of cell-laden scaffolds}

2.5.1. Live/dead staining-MDCK cells were cultured on scaffolds of different fiber diameters in the presence or absence of HGF, as described above. After a total of $48 \mathrm{~h}$ of culture, the constructs were rinsed with PBS and incubated with a mixture of Syto13 (1:1000) and propidium iodide (1:2000) in PBS for 15 min to stain live and dead cells, respectively. After an additional PBS wash to remove the unbound staining reagents, the constructs were imaged using a Zeiss LSM 710 confocal microscope. Five different confocal images were taken per sample and the number of clustered cells is defined as a group of more than five cells in close proximity. ${ }^{49}$

2.5.2. Immunofluorescence-MDCK cells were fixed using an ice-cold cytoskeleton stabilization buffer for $1 \mathrm{~min}$, incubated in freshly prepared with $4 \%$ paraformaldehyde/PBS solution for $15 \mathrm{~min}$, washed three times with PBS and finally incubated overnight in a permeabilization buffer (2\% BSA, $0.1 \%$ Triton X-100). Focal adhesions and cell-cell contacts were detected via immunostaining for vinculin, vimentin and E-cadherin, respectively. To this end, constructs were first incubated with primary antibodies (prepared in permeabilization buffer), monoclonal mouse anti-vinculin, monoclonal mouse antivimentin and purified mouse anti-E-cadherin, respectively for $90 \mathrm{~min}$. After a 3-min wash with PBS, samples were incubated with the secondary antibodies (1:200, in 2\% BSA), Alexa 488, Alexa 647 and Alexa 488-conjugated goat anti-mouse IgG (1:100 in 2\% BSA) for 45 min, respectively. After washing with copious PBS to remove unbound antibodies, the constructs were incubated with DAPI (1:5000) and Alexa-conjugated phalloidin (1: 1000) for 5 and $30 \mathrm{~min}$, respectively to counter stain cell nuclei and F-actin. The stained constructs were placed in Nunc chambers (Thermo Scientific, Rockford, IL) for imaging using a Zeiss LSM880 Multiphoton Confocal Microscope.

\subsection{Statistical analysis}

All the quantitative data obtained were analyzed using one-way analysis of variance (ANOVA) to compare the means of different data sets within each experiment from at least three repeats. Errors were expressed as the standard error of the mean. A value of $p<0.05$ was considered to be statistically significant. 


\section{Results}

\subsection{Fabrication and modification of microfibrous scaffolds}

PCL scaffolds were fabricated employing standard electrospinning protocols. Owing to the ability of the PCL fibers to adsorb and retain the CellTracker ${ }^{\mathrm{TM}}$ dye, the fibrous morphology can be readily seen under a confocal microscope (Fig 1A, C). Alteration of electrospinning conditions resulted in the creation of scaffolds with small (Fig 1A, B) and large (Fig 1C, D) fiber diameters. In both cases, the flexible PCL fibers are randomly oriented and intimately entangled to produce scaffolds with variable interstitial pores. Regions where adjacent fibers cross show an enhanced fluorescent signal. Analysis of the SEM images (Fig 1B, D) by DiameterJ revealed that fibers spun from $12 \mathrm{wt} \% \mathrm{DCM} / \mathrm{DMF}$ had an average diameter of $0.52 \pm 0.26 \mu \mathrm{m}$, whereas those obtained from $15 \mathrm{wt} \%$ chloroform solution had an average diameter of $5.02 \pm 0.39 \mu \mathrm{m}$ (Fig. 1E, F). While the surface of the 0.5 - $\mu \mathrm{m}$ fibers is relatively smooth, nanoscale grooves and pores can be found on the 5- $\mu \mathrm{m}$ fibers (Fig. 1D). Analysis of the SEM images by ImageJ revealed an average inter fiber pore size of $3.8 \pm 1.1 \mu \mathrm{m}^{2}$ and $169.1 \pm 32.0 \mu \mathrm{m}^{2}$, for small and large diameter fibers, respectively.

To promote integrin-mediated cell-scaffold interactions, fibrous scaffolds were subjected to a series of surface modifications (Fig. 2A) to install the cell-adhesive RGD peptide covalently. First, the scaffolds were subjected to aminolysis with HMD at ambient temperature to immobilize reactive amines. ${ }^{45}$ A time-course study using ninhydrin assay (Fig. S3) confirmed the need to prolong the treatment time to $24 \mathrm{~h}$ to ensure abundant amine functionality of the substrate. The covalent immobilization of primary amines on the PCL films was further confirmed by FT-IR analyses, based on the additional amide I and amide II peaks at 1,640 and $1,540 \mathrm{~cm}^{-1}$, as well as the $\mathrm{N}-\mathrm{H}$ stretch at $3,340 \mathrm{~cm}^{-1}$, as compared to the pristine PCL fibers (Fig. 2B). ${ }^{50}$. The moderate reduction in water contact angle from 77.2 \pm 1.8 degrees for silicon-supported PCL films to $61.6 \pm 0.4$ degrees for $\mathrm{PCL}-\mathrm{NH}_{2}$ provides additional evidence on the alteration of surface functionality.

Subsequent activation of surface amines with Sulfo-SMCC further improved the substrate hydrophilicity, with the average contact angle reduced to $33.6 \pm 3.4$ degrees. The surface immobilized maleimide group was utilized as the reactive handles for the covalent conjugation of the cysteine-tagged RGD peptide, synthesized and purified following standard procedures (Fig. S1, S2). XPS analysis of silicon supported films revealed the presence of sulfur and nitrogen peaks at a binding energy of $168.4 \mathrm{eV}$ (S2p) and $399.2 \mathrm{eV}$ (N1s), respectively (Fig. 2C) for PCL-RGD samples that are absent from the starting PCL substrates. The introduction of charged amino acid residues to PCL rendered the substrate even more hydrophilic, with an average water contact angle of $14.0 \pm 3.0$ degrees. Finally, the presence of the RGD peptide on the modified PCL scaffold was confirmed by confocal imaging via tryptophan fluorescence (Fig. 3). While the PCL scaffold exhibits minimal fluorescence signals, strong and uniform tryptophan fluorescence was detected on the surface of individual fibers from RGD-treated samples. PCL degradation is minimal during surface modification and peptide conjugation since the fiber diameter did not change significantly before and after each step of treatment (data not shown). 


\subsection{Attachment of MDCK cells on fibrous PCL scaffolds}

Our electrospinning and surface modification procedures led to straightforward production of fibrous scaffolds with micron and submicron sized fibers and consistent surface presentation of integrin binding peptides. To evaluate the role of surface immobilized RGD on cell attachment, MDCK cells were incubated on small and large diameter scaffolds with or without RGD conjugation in EMEM media containing 0.5\% FBS. Confocal imaging (Fig. 4A) showed that $2 \mathrm{~h}$ post seeding, cells on pristine $0.5 \mu \mathrm{m}$ fibers were predominantly round with juxtanuclear F-actin staining. On RGD-containing fibers cells were spread out with elongated F-actin-containing projections. Similarly, on $5 \mu \mathrm{m}$ fibers, cell spreading was observed on RGD-containing fibers. Quantification of the confocal images using ImageJ, in terms of cell spreading (Fig. 4B), cell circularity (Fig. 4C) and the average number of cells attached to the scaffold per $\mathrm{mm}^{2}$ surface area (Fig. 4D), confirmed that cell attachment and spreading on these scaffolds are strongly dependent on surface chemistry, irrespective of fiber diameter and/or the inter-fiber pore size. Statistically significant difference was observed between scaffolds with and without RGD $(\mathrm{p}<0.05)$, whereas the difference between small and large diameter fibers was not significant ( $p>0.05)$. Thus, the RGD presentation, not the fiber diameter, is involved in the initial attachment and spreading of MDCK cells. Subsequent investigations were carried out using RGD-modified scaffolds.

\subsection{Induction of EMT on MDCK cells grown on fibrous PCL scaffolds}

Fibrous PCL scaffolds were cytocompatible, as evidenced by the absence of red stained cells from live/dead staining (Fig. 5A). While cell growth and morphology were independent of fiber diameter $2 \mathrm{~h}$ post seeding, by $36 \mathrm{~h}$, there was a prominent difference in the growth pattern and cell morphology. On $0.5 \mu \mathrm{m}$ fibers, MDCK cells grew as compact colonies containing cuboidal cells (Fig. 5A(i)). By contrast, cells were elongated and grew separated from each other (Fig. 5A(iii)) on $5 \mu \mathrm{m}$ fibers. Fewer colonies were observed on large diameter fibers and cells in these colonies were loosely arranged, with cells at the periphery showing elongated fibroblast-like phenotype reminiscent of EMT (Fig. 5A(iii), circled in red).

HGF, also referred to as scatter factor, is known to induce EMT in MDCK cells. ${ }^{23}, 51$ To test the response of fiber grown MDCK cells to HGF, cells were treated with HGF at $36 \mathrm{~h}$ and grew for an additional $12 \mathrm{~h}$. HGF induced cell scattering on $0.5 \mu \mathrm{m}$ fiber scaffolds (Fig $5 \mathrm{~A}(\mathrm{ii})$, red rectangle). Strikingly, no significant differences in cell morphology and growth pattern were observed between control and HGF treated samples (compare Fig. 5A(iii) and (iv)) when MDCK cells were cultured on the $5 \mu \mathrm{m}$ scaffolds. Image analysis and quantification revealed that the number of compact colonies was 3 times more on the $0.5 \mu \mathrm{m}$ fibers than on the $5 \mu \mathrm{m}$ counterparts in the absence of HGF (Fig. 5B). While HGF did not induce significant changes in the number of cell clusters grown on $5 \mu \mathrm{m}$ fibers, the number of cell clusters grown on $0.5 \mu \mathrm{m}$ fibers was reduced by a factor of 5 upon HGF treatment.

Confocal imaging of the cell-laden scaffolds revealed that on the $0.5 \mu \mathrm{m}$ scaffold, cells formed discrete colonies of more than 15 cells, with cortical F-actin delineating the borders between adjacent cells (Fig. 6A, solid arrow). Upon HGF stimulation, these cells adopt a more fibroblastic morphology and some developed extended and long F-actin-containing 
processes that span across multiple randomly entangled fibers (Fig. 6B, dotted arrow). On the $5 \mu \mathrm{m}$ scaffold, a close association of cells with individual fibers was observed both in the presence or absence of HGF. Strikingly, on these scaffolds, cells with spindle shaped morphology wrapped around individual fibers (Fig. 6C, D, dotted arrow). In areas where neighboring fibers cross over, cells aggregated to form multicellular networks containing 24 cells (Fig. 6C, D, arrow heads). Individual cells can also be found at the crossover point bridging adjacent fibers. Taken together, these results are consistent with the notion that growth of MDCK cells for a longer period of time on $5 \mu \mathrm{m}$ fibers induces EMT-like phenotype, and addition of HGF does not produce further morphological changes.

\subsection{Expression of EMT markers by MDCK cells grown on fibrous PCL scaffolds}

Phenotypic changes that occur during EMT are accompanied by the expression of markers that facilitate cell migration and invasive behavior. Downregulation of the cell adhesion molecule E-cadherin is a common feature of EMT. ${ }^{52}$ Unstimulated MDCK cells cultured on $0.5 \mu \mathrm{m}$ fibers displayed a closely packed cell monolayer with intense E-cadherin and F-actin staining co-localizing at the areas of lateral cell-cell contacts (Fig. 7A). When stimulated with HGF, E-cadherin staining diminished (Fig. 7B) and individual spindle shaped cells detached from their neighbors (Fig. 7B(ii)). E-cadherin was detected both in the cytoplasm, as punctuated dots, and at the periphery of the cells (Fig. $7 \mathrm{~B}(\mathrm{v})$ ), indicating the disintegration of cell-cell adhesions. On the other hand, unstimulated cells on $5 \mu \mathrm{m}$ fibers displayed spindle shaped morphology with weak E-Cadherin staining (Fig. 7C). HGF stimulation did not significantly alter the cell morphology or E-cadherin staining pattern (Fig. 7D).

While E-cadherin is downregulated, vimentin expression is upregulated during EMT. Vimentin is an intermediate filament protein expressed in mesenchymal cells and widely used as an EMT marker. ${ }^{53}$ Cells cultured on $0.5 \mu \mathrm{m}$ fibers displayed cobblestone morphology stained faintly for vimentin (Fig. 8A(ii)). Circumferential actin staining was distinctly observed at the cell-cell contact region (Fig. 8A(iii-v)). HGF addition caused cells to adopt a spindle shaped morphology and significantly increased cellular expression of vimentin and diminished circumferential actin expression (Fig. 8B(ii-v)). Actin stress fibers were visible at higher magnification (Fig. S4, solid arrow). On $5 \mu \mathrm{m}$ fibers, the unstimulated cells were spindle shaped, similar to HGF-stimulated cells. Immunostaining revealed higher vimentin expression compared to untreated cells cultured on $0.5 \mu \mathrm{m}$ fibers (compare Fig. 8A (ii) and 8C (ii) with Fig. 8D(ii)). Actin staining was primarily observed as actin cables running through the extended projections of the cells (Fig. S4, solid arrow).

Vinculin is a specialized protein present at the adherens junctions that mediates cell-cell contacts and focal adhesions that controls cell-to-substrate attachment. ${ }^{54-55}$ Immunostaining of MDCK cells cultured on $0.5 \mu \mathrm{m}$ fibers without HGF showed intense vinculin staining, as discrete green dots, at the cell-cell junctions along the borders delineated by intense F-actin staining (Fig. 9A). Upon HGF stimulation, vinculin signals were no longer localized at the cell-cell junctions and were distributed randomly at the elongated cell projections stained for actin (Fig. 9B). On $5 \mu \mathrm{m}$ fibers vinculin staining was similar to HGF treated cells grown on $0.5 \mu \mathrm{m}$ fibers (compare Fig. 9C and 9D, with 9B). 
Collectively, our results demonstrate that cells cultured on micron-sized fibers predominantly adopt a fibroblastic phenotype and exhibit minimal response to HGF stimulation, while those on submicron-sized fibers undergo distinct HGF-induced EMT.

\section{Discussion}

Owing to the ease of fabrication and the structural similarity to the natural ECM, electrospun fibrous scaffolds have been widely exploited in tissue engineering/regenerative medicine applications. Previous studies highlighted the influence of fiber diameter on the spreading, migration and differentiation of osteoblasts, ${ }^{48,56}$ the chondrogenic differentiation of human mesenchymal stem cells, ${ }^{57-58}$ the functional polarization of macrophages ${ }^{59}$ and the differentiation and proliferation of neural stem cells. ${ }^{60}$ The overall conclusion is that cells alter their behaviors based on their perception and interpretation of the physical dimension of individual fibers, although there is no general consensus as to whether micro- or nanosized fibers are more conducive to the desired differentiation or phenotype.

EMT is an important biological process in embryonic development, cancer metastasis and tissue fibrosis. During EMT, normal epithelial cells change the typical cuboidal morphology, weaken their cell-cell junctions and detach from the epithelial sheet. The transformed cells adopt irregular and more elongated shape, develop integrin mediated adhesion to the ECM and become motile and invasive. ${ }^{49,}{ }^{61} \mathrm{HGF}$ is a potent scatter factor that has a marked stimulatory effect on cell motility of MDCK cells, but not on their growth. ${ }^{23}$ While matrix composition, rigidity and substrate curvature have been shown to define cell phenotype and to mediate cell attachment and scattering, the effects of fiber diameter on EMT have not been investigated despite the fact that ECM synthesis and remodeling during development and diseases inevitably alter the thickness and diameter of fibrous proteins. ${ }^{62}$

Herein, electrospun fibrous scaffolds with an average fiber diameter of $5 \mu \mathrm{m}$ and $0.5 \mu \mathrm{m}$ are fabricated employing standard spinning conditions. In the native ECM under normal conditions, collagen molecules self-assemble into fibrils of 10-300 nm, which further aggregate to form collagen fibers of $0.5-3 \mu \mathrm{m} .{ }^{63-64}$ An increase in the thickness of collagen fibers is often associated with certain pathology, such as fibrosis. ${ }^{65-66}$ Therefore, two different scaffolds with a 10 -fold difference in fiber diameter were fabricated to reflect the dimensions of native collagen fibers in healthy and diseased tissues. The chosen fiber diameters resulted in scaffolds with an average pore size smaller or larger than the average size of a rounded MDCK cells, thereby promoting or preventing cell-cell adhesion. Further, cell-adhesive RGD peptide was conjugated to the fibrous scaffold to promote integrinmediated cell-scaffold interaction. RGD modification significantly improved the surface hydrophilicity, promoting the spreading and growth of MDCK cells. A relatively low cell seeding density was chosen to ensure the formation of compact colonies of MDCK cells on both scaffolds. No significant cell infiltration into the scaffold was observed.

Standard electrospinning protocols do not allow independent control of fiber diameter and inter-fiber pore size, and it is not possible to match the pore size for scaffolds with a large fiber diameter with those consisting of smaller diameter fibers. In general, scaffolds with smaller diameter fibers are denser than those with larger diameter fibers. Such a positive 
correlation has been observed in the native ECM ${ }^{67}$ Our results show that the fiber diameter, and consequently the average pore size, has a profound effect on the initial attachment and clustering of MDCK cells. The $5 \mu \mathrm{m}$ scaffold promotes more intimate cell-fiber interactions, as evidenced by individual cells wrapping around and elongating along individual fibers. The relatively large pore size prohibits the formation of a cohesive monolayer spanning multiple fibers with close cell-cell contacts; only in regions where adjacent fibers cross over closely can multicellular bridges form. On the other hand, cells perceive the $0.5 \mu \mathrm{m}$ scaffold as a collective mesh as individual fibers are comparable in size to subcellular processes. Consequently, cells seeded on such scaffolds form more intimate cell-cell contacts, as evidenced by the defined cobblestone morphology. In the cell clusters, individually attached cells span across multiple randomly entangled fiber and cell processes at the edge of cell cluster also span across multiple fibers. Such differential cell-scaffold interactions define the initial cell phenotype, with cells on the large diameter fibers being more mesenchymal-like, whereas those on the small diameter fibers are more epithelial like.

The scaffold-guided cell attachment not only defines the initial cell morphology and phenotype, but also mediates subsequent HGF-induced EMT. Previous studies ${ }^{21}$ have shown that HGF-stimulated motile response of MDCK cells involves the initial expansion of each colony during the first 4-6 h, followed by the spreading and scattering of individual cells that break off from their neighboring cells. The reduced expression of E-cadherin, enhanced expression of vimentin and change of circumferential actin into stress fibers confirmed that MDCK epithelial cells grown on large diameter fibers already adopted a fibroblastic phenotype in the absence of HGF ${ }^{49,}{ }^{68-69}$ Because cells cultured on large diameter fibers did not develop distinct cell-cell adhesion, HGF addition did not lead to significant change in cell phenotype, as evidenced by the minimal changes in cellular expression of EMT markers with or without HGF stimulation. Although HGF can have profound effects on mesenchymal cells, this is not the focus of our current investigation. By contrast, cells cultured on smaller diameter fibers are more epithelial-like and are clustered with cell-cell adhesions, and they are more responsive to the HGF treatment. Our immunostaining experiments clearly show the HGF-induced disruption of E-cadherin expression. The upregulation of vimentin expression is also significant. Our results suggest that biophysical cues of the scaffold not only determine the cell phenotype but also mediate the change of cell phenotype. In vivo, cells undergoing EMT lose their cell-cell contact, and in severe cases of fibrosis, such as in diabetic nephropathy, the transdifferentiated cells remain embedded in the $\mathrm{ECM}^{70}$ and morphologically resemble those grown the $5 \mu \mathrm{m}$ fibers.

Of note, fiber diameter may not be the only determinant of the EMT behaviors of MDCK cells; the migration capacity of the cells also depends on the cell-substrate adhesion. Earlier studies showed that the scattering of the cells depends on ECM concentration, ${ }^{71-72}$ and a recent study revealed that E-cadherin levels can counterbalance the effect of ECM density. ${ }^{12}$ In our case, scaffolds with submicron sized fibers may exhibit a higher ligand density, owing to the higher surface-to-volume ratio as compared to the larger diameter scaffold. The diffuse and punctuated vinculin staining from cells cultured on larger diameter scaffolds, both in the presence and absence of HGF, suggests the presence of moderate cell-matrix adhesion. The intense and punctuated vinculin staining from cells cultured on small diameter fibers in the absence of HGF confirm strong cell-cell adhesion. The diffuse vinculin staining 
that does co-localize with the F-actin signals at the cell projections indicates the presence of cell-matrix interaction. When stimulated with HGF, vinculin signals disappeared from the cell-cell junction, but are maintained at the focal adhesion with the substrate, giving rise to a motile, mesenchymal cell phenotype.

Despite the quantitative nature of the current study, our results unambiguously confirm that the fiber diameter is the predominant factor controlling the initial cell phenotype and the higher ligand density further reinforced the HGF mediated phenotypic change seen in the $0.5 \mu \mathrm{m}$ fibers. Therefore, nanofibrous scaffolds are a more suitable platform for establishing appropriate extracellular microenvironment for studying EMT during disease progression. Future investigations focusing on quantitative analyses of cell motility, mechanotransduction, as well as EMT-related genes and proteins, including various integrins, HGF downstream genes and known transcriptional EMT inducers, will reveal unknown mechanisms on fiber diameter-mediated EMT.

\section{Conclusion}

Cell-adhesive, micro/nano fibrous scaffolds were developed to provide an instructive environment for dissecting fundamental processes guiding EMT. Our study revealed that the attachment, clustering and scattering of MDCK cells are dependent on the diameter and surface chemistry of electrospun fibers. In the absence of HGF, MDCK cells tend to be more clustered and have a more cobblestone morphology when cultured on submicron sized fibrous scaffolds. With the addition of HGF, cells adopt a more spread-out, spindle-shaped morphology, indicating an epithelial to mesenchymal transition. Micron-sized fibers, on the other hand, promote intimate interactions between individual cells and isolated fibers, thereby fostering a more mesenchymal-like phenotype in the absence or presence of scattering factor. The strong correlation between fiber diameter, cell shape/morphology and phenotype underscores the importance of designing synthetic scaffolds with appropriate topographical features to regulate cell function and to foster desired cell differentiation.

\section{Supplementary Material}

Refer to Web version on PubMed Central for supplementary material.

\section{Acknowledgments}

We would like to thank Dr. D. Bruce Chase for his advice on FT-IR analysis, Dr. Jeffrey Caplan for his assistance with multiphoton confocal microscope and Dr. Ying Hao for her guidance in peptide synthesis and characterization. This work was supported in part by National Institutes of Health (NIDCR, R01 DE022969; NIDCD, R01 DC014461), the Osteo Science Foundation and the DuPont Company. We acknowledge the Delaware COBRE program (NIGMS, P30 GM110758) and the Delaware INBRE program (NIGMS, P20 GM103446) for instrumentation support.

\section{References}

1. Barrallo-Gimeno A, Nieto MA. The Snail genes as inducers of cell movement and survival: implications in development and cancer. Development. 2005; 132:3151-3161. [PubMed: 15983400]

2. Moreno-Bueno G, Portillo F, Cano A. Transcriptional regulation of cell polarity in EMT and cancer. Oncogene. 2008; 27:6958-6969. [PubMed: 19029937] 
3. Peinado H, Olmeda D, Cano A, Snail. Zeb and bHLH factors in tumour progression: an alliance against the epithelial phenotype? Nature Reviews Cancer. 2007; 7:415-428. [PubMed: 17508028]

4. Thiery JP, Sleeman JP. Complex networks orchestrate epithelial-mesenchymal transitions. Nature reviews Molecular cell biology. 2006; 7:131-142. [PubMed: 16493418]

5. Nakaya Y, Sukowati EW, Wu Y, Sheng G. RhoA and microtubule dynamics control cell-basement membrane interaction in EMT during gastrulation. Nature cell biology. 2008; 10:765-775. [PubMed: 18552836]

6. Martin AC, Kaschube M, Wieschaus EF. Pulsed contractions of an actin-myosin network drive apical constriction. Nature. 2009; 457:495-499. [PubMed: 19029882]

7. Choi SS, Diehl AM. Epithelial-to-Mesenchymal Transitions in the Liver. Hepatology (Baltimore, Md). 2009; 50:2007-2013.

8. Kalluri R, Weinberg RA. The basics of epithelial-mesenchymal transition. The Journal of Clinical Investigation. 2009; 119:1420-1428. [PubMed: 19487818]

9. Kalluri R, Neilson EG. Epithelial-mesenchymal transition and its implications for fibrosis. J Clin Invest. 2003; 112:1776-1784. [PubMed: 14679171]

10. Wolf K, Wu YI, Liu Y, Geiger J, Tam E, Overall C, Stack MS, Friedl P. Multistep pericellular proteolysis controls the transition from individual to collective cancer cell invasion. Nat Cell Biol. 2007; 9:893-904. [PubMed: 17618273]

11. Mason SD, Joyce JA. Proteolytic networks in cancer. Trends Cell Biol. 2011; 21:228-237. [PubMed: 21232958]

12. Kumar S, Das A, Sen S. Extracellular matrix density promotes EMT by weakening cell-cell adhesions. Molecular BioSystems. 2014; 10:838-850. [PubMed: 24481128]

13. Ridley AJ, Schwartz MA, Burridge K, Firtel RA, Ginsberg MH, Borisy G, Parsons JT, Horwitz AR. Cell migration: integrating signals from front to back. Science. 2003; 302:1704-1709. [PubMed: 14657486]

14. Baltimore D, Boldin MP, O’Connell RM, Rao DS, Taganov KD. MicroRNAs: new regulators of immune cell development and function. Nat Immunol. 2008; 9:839-845. [PubMed: 18645592]

15. Valastyan S, Weinberg RA. Tumor metastasis: molecular insights and evolving paradigms. Cell. 2011; 147:275-292. [PubMed: 22000009]

16. Boot-Handford RP, Tuckwell DS. Fibrillar collagen: the key to vertebrate evolution? A tale of molecular incest. Bioessays. 2003; 25:142-151. [PubMed: 12539240]

17. Paszek MJ, Zahir N, Johnson KR, Lakins JN, Rozenberg GI, Gefen A, Reinhart-King CA, Margulies SS, Dembo M, Boettiger D, Hammer DA, Weaver VM. Tensional homeostasis and the malignant phenotype. Cancer Cell. 2005; 8:241-254. [PubMed: 16169468]

18. Egeblad M, Rasch MG, Weaver VM. Dynamic interplay between the collagen scaffold and tumor evolution. Curr Opin Cell Biol. 2010; 22:697-706. [PubMed: 20822891]

19. Provenzano PP, Eliceiri KW, Campbell JM, Inman DR, White JG, Keely PJ. Collagen reorganization at the tumor-stromal interface facilitates local invasion. BMC Medicine. 2006; 4:115. [PubMed: 16412236]

20. Kauppila S, Stenback F, Risteli J, Jukkola A, Risteli L. Aberrant type I and type III collagen gene expression in human breast cancer in vivo. J Pathol. 1998; 186:262-268. [PubMed: 10211114]

21. Stoker M, Perryman M. An epithelial scatter factor released by embryo fibroblasts. J Cell Sci. 1985; 77:209-223. [PubMed: 3841349]

22. Montesano R, Matsumoto K, Nakamura T, Orci L. Identification of a fibroblast-derived epithelial morphogen as hepatocyte growth factor. Cell. 1991; 67:901-908. [PubMed: 1835669]

23. Tajima H, Matsumoto K, Nakamura T. Regulation of cell growth and motility by hepatocyte growth factor and receptor expression in various cell species. Exp Cell Res. 1992; 202:423-431. [PubMed: 1327854]

24. Raghavan S, Shen CJ, Desai RA, Sniadecki NJ, Nelson CM, Chen CS. Decoupling diffusional from dimensional control of signaling in 3D culture reveals a role for myosin in tubulogenesis. Journal of cell science. 2010; 123:2877-2883. [PubMed: 20682635] 
25. Garcia S, Sunyer R, Olivares A, Noailly J, Atencia J, Trepat X. Generation of stable orthogonal gradients of chemical concentration and substrate stiffness in a microfluidic device. Lab Chip. 2015; 15:2606-2614. [PubMed: 25977997]

26. Harada K, Negishi M, Katoh H. HGF-induced serine 897 phosphorylation of EphA2 regulates epithelial morphogenesis of MDCK cells in 3D culture. J Cell Sci. 2015; 128:1912-1921. [PubMed: 25908849]

27. Bhattarai SR, Bhattarai N, Yi HK, Hwang PH, Cha DI, Kim HY. Novel biodegradable electrospun membrane: scaffold for tissue engineering. Biomaterials. 2004; 25:2595-2602. [PubMed: 14751745]

28. Vasita R, Katti DS. Nanofibers and their applications in tissue engineering. Int J Nanomedicine. 2006; 1:15-30. [PubMed: 17722259]

29. Sill TJ, von Recum HA. Electrospinning: applications in drug delivery and tissue engineering. Biomaterials. 2008; 29:1989-2006. [PubMed: 18281090]

30. Tong Z, Sant S, Khademhosseini A, Jia X. Controlling the fibroblastic differentiation of mesenchymal stem cells via the combination of fibrous scaffolds and connective tissue growth factor. Tissue Eng Part A. 2011; 17:2773-2785. [PubMed: 21689062]

31. Tong Z, Duncan RL, Jia X. Modulating the behaviors of mesenchymal stem cells via the combination of high-frequency vibratory stimulations and fibrous scaffolds. Tissue Eng Part A. 2013; 19:1862-1878. [PubMed: 23516973]

32. Tong Z, Zerdoum AB, Duncan RL, Jia X. Dynamic vibration cooperates with connective tissue growth factor to modulate stem cell behaviors. Tissue Eng Part A. 2014; 20:1922-1934. [PubMed: 24456068]

33. Eldsäter C, Erlandsson B, Renstad R, Albertsson A-C, Karlsson S. The biodegradation of amorphous and crystalline regions in film-blown poly ( $\varepsilon$-caprolactone). Polymer. 2000; 41:12971304.

34. Gunatillake PA, Adhikari R. Biodegradable synthetic polymers for tissue engineering. Eur Cell Mater. 2003; 5:1-16. [PubMed: 14562275]

35. Hutmacher DW. Scaffold design and fabrication technologies for engineering tissues - state of the art and future perspectives. Journal of Biomaterials Science, Polymer Edition. 2001; 12:107-124. [PubMed: 11334185]

36. Williams JM, Adewunmi A, Schek RM, Flanagan CL, Krebsbach PH, Feinberg SE, Hollister SJ, Das S. Bone tissue engineering using polycaprolactone scaffolds fabricated via selective laser sintering. Biomaterials. 2005; 26:4817-4827. [PubMed: 15763261]

37. Zhu Y, Gao C, Liu X, Shen J. Surface Modification of Polycaprolactone Membrane via Aminolysis and Biomacromolecule Immobilization for Promoting Cytocompatibility of Human Endothelial Cells. Biomacromolecules. 2002; 3:1312-1319. [PubMed: 12425670]

38. Tsai W-B, Chen C-H, Chen J-F, Chang K-Y. The effects of types of degradable polymers on porcine chondrocyte adhesion proliferation and gene expression. Journal of Materials Science: Materials in Medicine. 2006; 17:337-343. [PubMed: 16617412]

39. Ishaug-Riley SL, Okun LE, Prado G, Applegate MA, Ratcliffe A. Human articular chondrocyte adhesion and proliferation on synthetic biodegradable polymer films. Biomaterials. 1999; 20:2245-2256. [PubMed: 10614931]

40. Garcia AJ, Reyes CD. Bio-adhesive surfaces to promote osteoblast differentiation and bone formation. J Dent Res. 2005; 84:407-413. [PubMed: 15840774]

41. Takada Y, Ye X, Simon S. The integrins. Genome Biol. 2007; 8:215. [PubMed: 17543136]

42. Grieshaber SE, Farran AJ, Lin-Gibson S, Kiick KL, Jia X. Synthesis Characterization of ElastinMimetic Hybrid Polymers with Multiblock. Alternating Molecular Architecture and Elastomeric Properties. Macromolecules. 2009; 42:2532-2541. [PubMed: 19763157]

43. Grieshaber SE, Farran AJ, Bai S, Kiick KL, Jia X. Tuning the properties of elastin mimetic hybrid copolymers via a modular polymerization method. Biomacromolecules. 2012; 13:1774-1786. [PubMed: 22533503]

44. Liu S, Zhang H, Remy RA, Deng F, Mackay ME, Fox JM, Jia X. Meter-long multiblock copolymer microfibers via interfacial bioorthogonal polymerization. Adv Mater. 2015; 27:27832790. [PubMed: 25824805] 
45. Zhu Y, Mao Z, Shi H, Gao C. In-depth study on aminolysis of poly( $\varepsilon$-caprolactone): Back to the fundamentals. Science China Chemistry. 2012; 55:2419-2427.

46. Zhang H, Lin C-Y, Hollister SJ. The interaction between bone marrow stromal cells and RGDmodified three-dimensional porous polycaprolactone scaffolds. Biomaterials. 2009; 30:40634069. [PubMed: 19487019]

47. Hotaling NA, Bharti K, Kriel H, Simon CG Jr. DiameterJ: A validated open source nanofiber diameter measurement tool. Biomaterials. 2015; 61:327-338. [PubMed: 26043061]

48. Sisson K, Zhang C, Farach-Carson MC, Chase DB, Rabolt JF. Fiber diameters control osteoblastic cell migration and differentiation in electrospun gelatin. J Biomed Mater Res A. 2010; 94:13121320. [PubMed: 20694999]

49. de Rooij J, Kerstens A, Danuser G, Schwartz MA, Waterman-Storer CM. Integrin-dependent actomyosin contraction regulates epithelial cell scattering. The Journal of Cell Biology. 2005; 171:153-164. [PubMed: 16216928]

50. Causa F, Battista E, Della Moglie R, Guarnieri D, Iannone M, Netti PA. Surface Investigation on Biomimetic Materials to Control Cell Adhesion: The Case of RGD Conjugation on PCL. Langmuir. 2010; 26:9875-9884. [PubMed: 20349926]

51. Ridley AJ, Comoglio PM, Hall A. Regulation of scatter factor/hepatocyte growth factor responses by Ras Rac, and Rho in MDCK cells. Molecular and Cellular Biology. 1995; 15:1110-1122. [PubMed: 7823927]

52. Balkovetz DF, Pollack AL, Mostov KE. Hepatocyte growth factor alters the polarity of MadinDarby canine kidney cell monolayers. J Biol Chem. 1997; 272:3471-3477. [PubMed: 9013593]

53. Mendez MG, Kojima S, Goldman RD. Vimentin induces changes in cell shape motility and adhesion during the epithelial to mesenchymal transition. FASEB J. 2010; 24:1838-1851. [PubMed: 20097873]

54. Soong HK. Vinculin in focal cell-to-substrate attachments of spreading corneal epithelial cells. Arch Ophthalmol. 1987; 105:1129-1132. [PubMed: 3115239]

55. Palovuori R, Eskelinen S. Role of vinculin in the maintenance of cell-cell contacts in kidney epithelial MDBK cells. Eur J Cell Biol. 2000; 79:961-974. [PubMed: 11152287]

56. Badami AS, Kreke MR, Thompson MS, Riffle JS, Goldstein AS. Effect of fiber diameter on spreading proliferation and differentiation of osteoblastic cells on electrospun poly(lactic acid) substrates. Biomaterials. 2006; 27:596-606. [PubMed: 16023716]

57. Wise JK, Yarin AL, Megaridis CM, Cho M. Chondrogenic differentiation of human mesenchymal stem cells on oriented nanofibrous scaffolds: engineering the superficial zone of articular cartilage. Tissue Eng Part A. 2009; 15:913-921. [PubMed: 18767972]

58. Bean AC, Tuan RS. Fiber diameter and seeding density influence chondrogenic differentiation of mesenchymal stem cells seeded on electrospun poly(epsilon-caprolactone) scaffolds. Biomed Mater. 2015; 10:015018. [PubMed: 25634427]

59. Garg K, Pullen NA, Oskeritzian CA, Ryan JJ, Bowlin GL. Macrophage functional polarization (M1/M2) in response to varying fiber and pore dimensions of electrospun scaffolds. Biomaterials. 2013; 34:4439-4451. [PubMed: 23515178]

60. Christopherson GT, Song H, Mao HQ. The influence of fiber diameter of electrospun substrates on neural stem cell differentiation and proliferation. Biomaterials. 2009; 30:556-564. [PubMed: 18977025]

61. Shook D, Keller R. Mechanisms mechanics and function of epithelial-mesenchymal transitions in early development. Mechanisms of development. 2003; 120:1351-1383. [PubMed: 14623443]

62. Ushiki T. Collagen fibers reticular fibers and elastic fibers. A comprehensive understanding from a morphological viewpoint. Arch Histol Cytol. 2002; 65:109-126. [PubMed: 12164335]

63. Alberts, B.; Johnson, A.; Lewis, J.; Raff, M.; Roberts, K.; Walter, P. Molecular Biology of the Cell. 4. Garland Science; New York: 2002.

64. Humphrey JD, Dufresne ER, Schwartz MA. Mechanotransduction and extracellular matrix homeostasis. Nat Rev Mol Cell Biol. 2014; 15:802-812. [PubMed: 25355505]

65. Ehrlich HP, Desmouliere A, Diegelmann RF, Cohen IK, Compton CC, Garner WL, Kapanci Y, Gabbiani G. Morphological and immunochemical differences between keloid and hypertrophic scar. Am J Pathol. 1994; 145:105-113. [PubMed: 8030742] 
66. Verhaegen PDHM, Van Zuijlen PPM, Pennings NM, Van Marle J, Niessen FB, Van Der Horst CMAM, Middelkoop E. Differences in collagen architecture between keloid hypertrophic scar normotrophic scar and normal skin: An objective histopathological analysis. Wound Repair and Regeneration. 2009; 17:649-656. [PubMed: 19769718]

67. Schwartz MA, Chen CS. Cell biology. Deconstructing dimensionality. Science. 2013; 339:402404. [PubMed: 23349278]

68. Zeisberg M, Neilson EG. Biomarkers for epithelial-mesenchymal transitions. The Journal of clinical investigation. 2009; 119:1429-1437. [PubMed: 19487819]

69. Kokkinos MI, Wafai R, Wong MK, Newgreen DF, Thompson EW, Waltham M. Vimentin and epithelial-mesenchymal transition in human breast cancer-observations in vitro and in vivo. Cells Tissues Organs. 2007; 185:191-203. [PubMed: 17587825]

70. Rajasekaran SA, Huynh TP, Wolle DG, Espineda CE, Inge LJ, Skay A, Lassman C, Nicholas SB, Harper JF, Reeves AE. Na K-ATPase subunits as markers for epithelial-mesenchymal transition in cancer and fibrosis. Molecular cancer therapeutics. 2010; 9:1515-1524. [PubMed: 20501797]

71. Clark P. Modulation of scatter factor/hepatocyte growth factor activity by cell-substratum adhesion. Journal of Cell Science. 1994; 107:1265-1275. [PubMed: 7523427]

72. Sander EE, van Delft S, Jean P, Reid T, van der Kammen RA, Michiels F, Collard JG. Matrixdependent Tiam1/Rac signaling in epithelial cells promotes either cell-cell adhesion or cell migration and is regulated by phosphatidylinositol 3-kinase. J Cell Bio. 1998; 143:1385-1398. [PubMed: 9832565] 

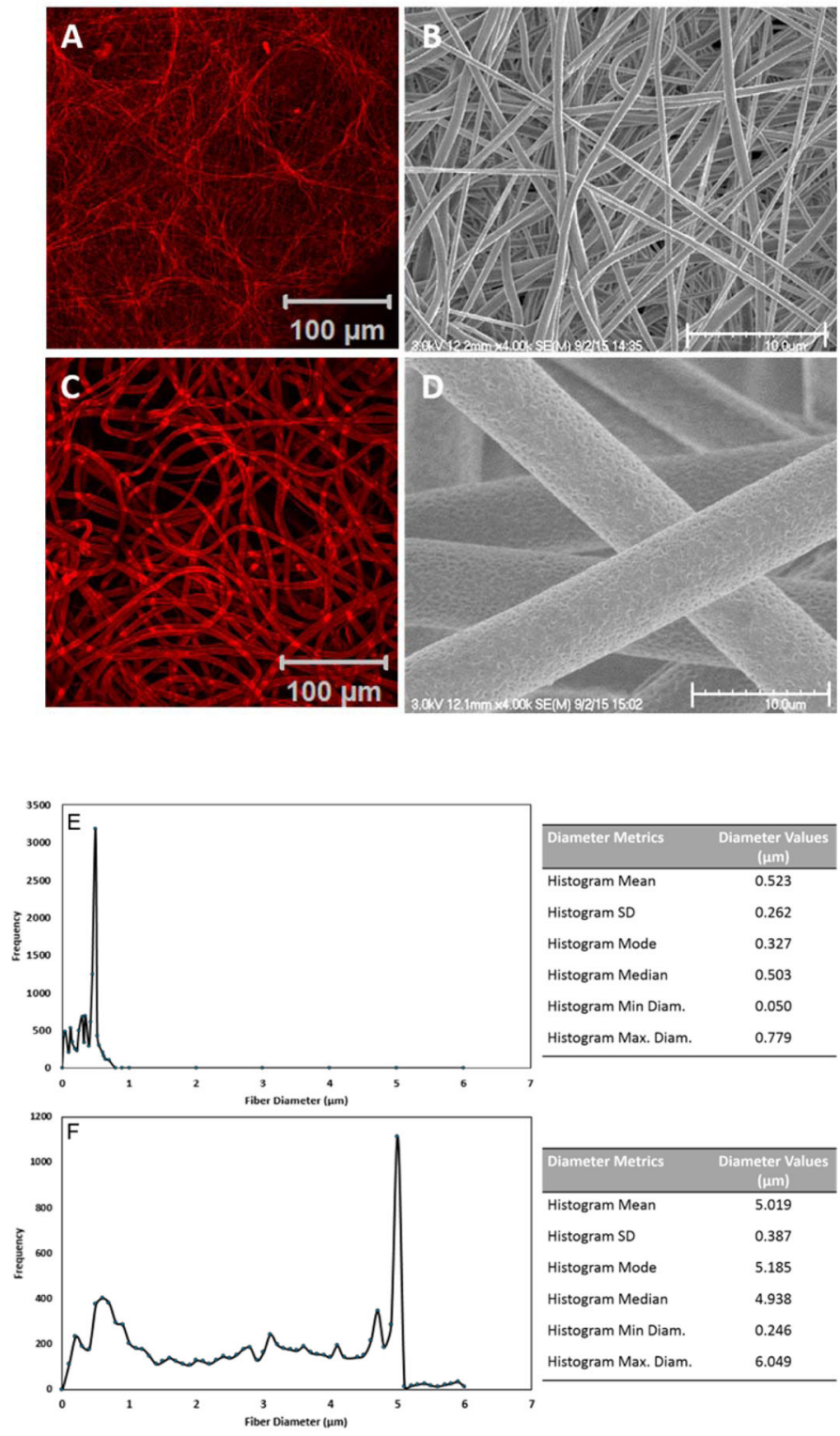

Fig. 1.

Characterization of electrospun fibrous scaffolds by confocal microscope (A, C) and scanning electron microscope (SEM, B, D). Scaffolds were stained with CellTracker ${ }^{\mathrm{TM}}$ Red or sputter-coated with platinum prior to confocal and SEM imaging, respectively. Fiber diameter (E, F) was determined from SEM images using DiameterJ's histogram analysis. Fibrous scaffolds with an average diameter of 0.5 (A, B, E) and $5 \mu \mathrm{m}(\mathrm{C}, \mathrm{D}, \mathrm{F})$ are fabricated employing different electrospinning parameters. 

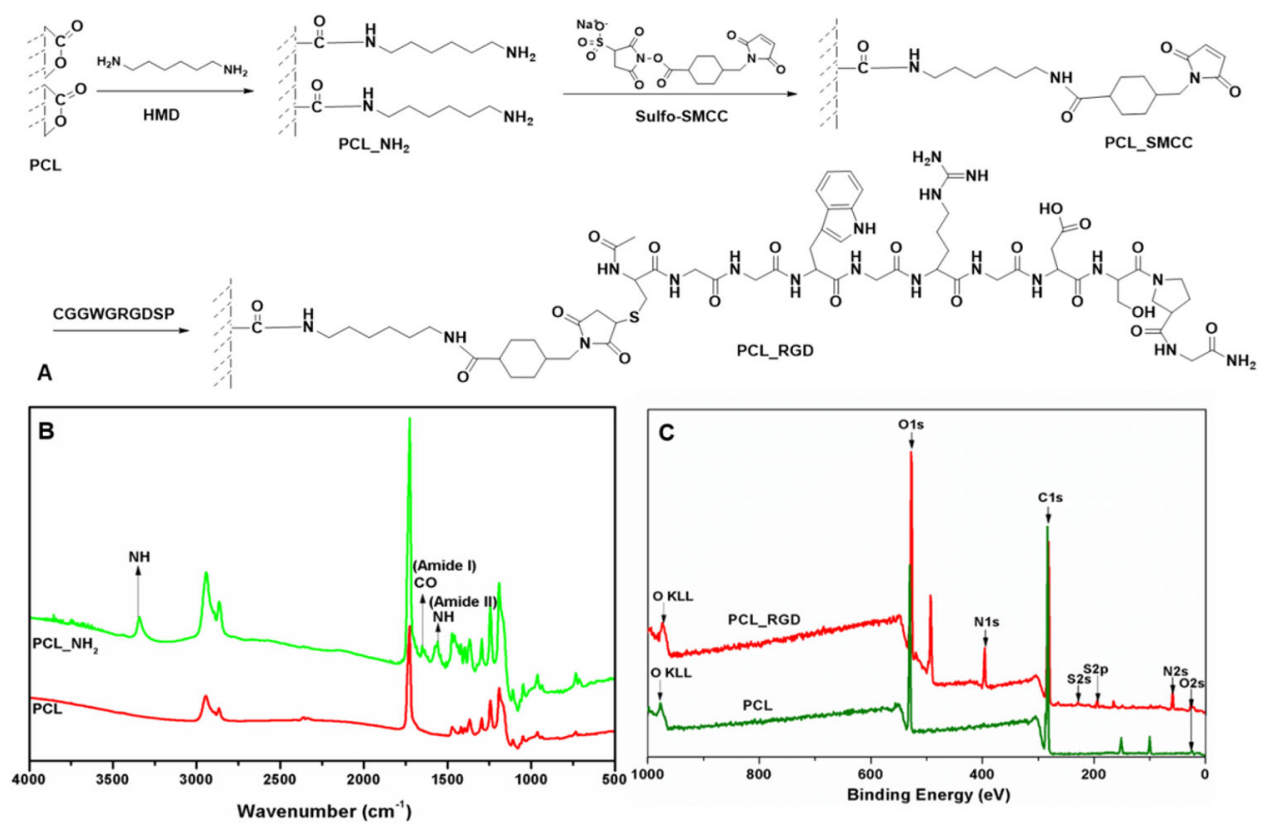

Fig. 2.

Modification and characterization of PCL substrates. Cell adhesive peptide

(CGGWGRGDSPG: RGD-SH) was covalently conjugated to the surface of PCL fibers (A). The chemical transformations were monitored by Fourier Transform Infrared Spectroscopy (FT-IR, B) and X-ray photoelectron spectroscopy (XPS, C). Spun cast PCL films were used for surface analysis to eliminate the topographical complications. Compared to PCL, aminolyzed PCL (PCL-NH ${ }_{2}$ ) shows characteristic amide and amine peaks (B) and RGDconjugated PCL (PCL-RGD) shows characteristic S and N peaks (C). 

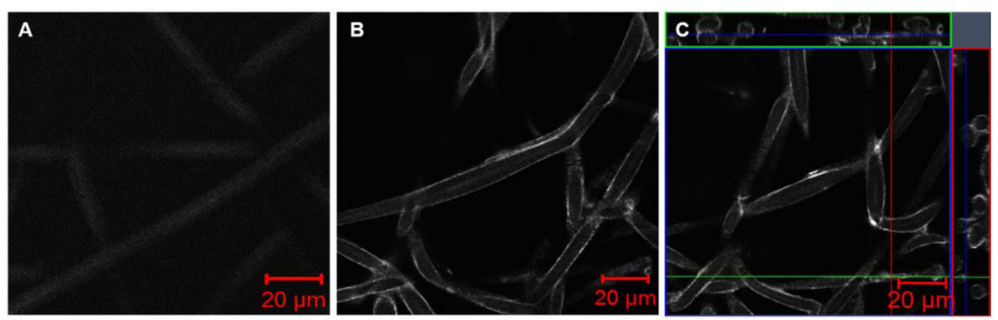

Fig. 3.

Characterization of peptide immobilization by confocal imaging based on tryptophan fluorescence (Excitation: $280 \mathrm{~nm}$; Emission: $350 \mathrm{~nm}$ ). The bright tryptophan signal on the outer surface of the peptide-modified fibers (B and C) is absent on the pristine PCL fibers (A). The cross sectional view of the peptide-modified fibers $(C)$ confirms the uniform peptide conjugation on the fiber surface. 

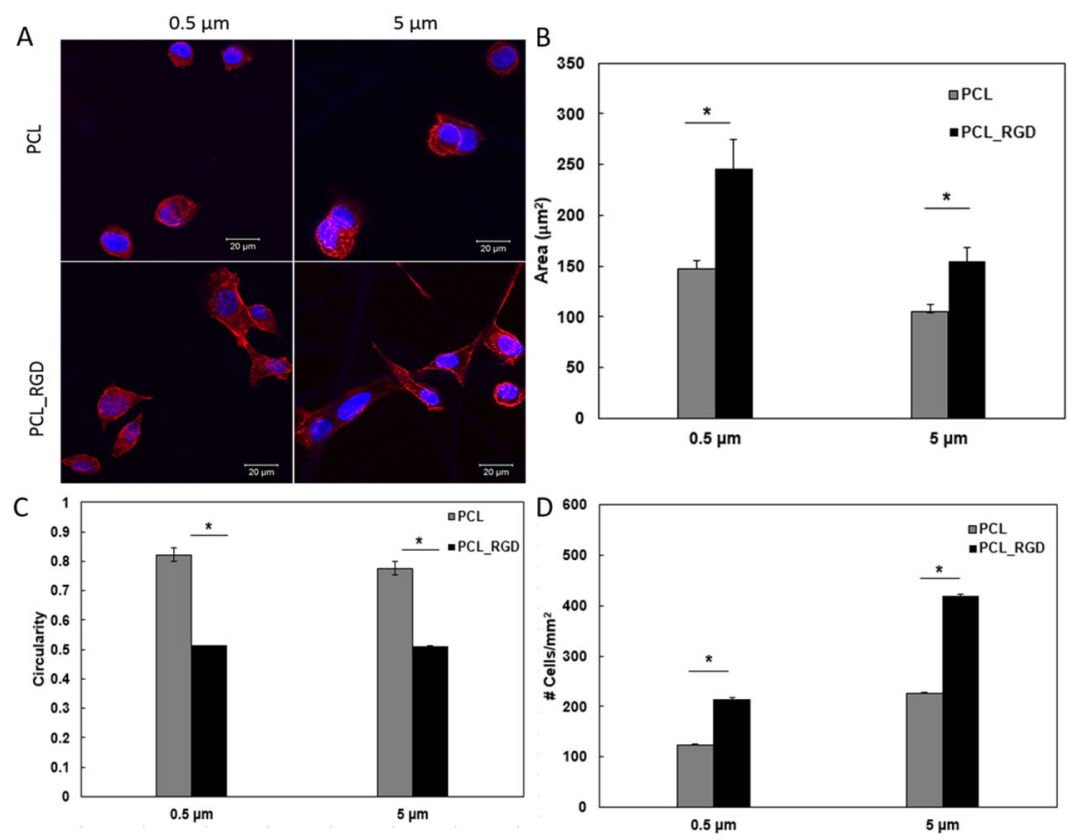

Fig. 4.

Characterization of the initial attachment and spreading of MDCK cells on small and large diameter fibers, with or without RGD conjugation. (A): Confocal images of MDCK cells cultured on PCL-based scaffolds (40x). Red: F-actin; Blue: nuclei. (B): Cell spreading as a function of fiber diameter and surface chemistry; (C): Cell circularity as a function of fiber diameter and surface chemistry. The circularity is defined as $4 \pi \times a r e a /$ perimeter $^{2}$. (D): Average number of cells attached to the scaffold per $\mathrm{mm}^{2}$ surface area. Quantification was carried out using ImageJ software based on five separate $1,024 \times 1,024 \mu^{2}$ confocal images. *Significantly different $(\mathrm{p}<0.05$, ANOVA) from RGD conjugated scaffolds. No significant difference was observed between small and large diameter fibers $(p>0.05)$. Error represents standard error of the mean of 3 repeats. 

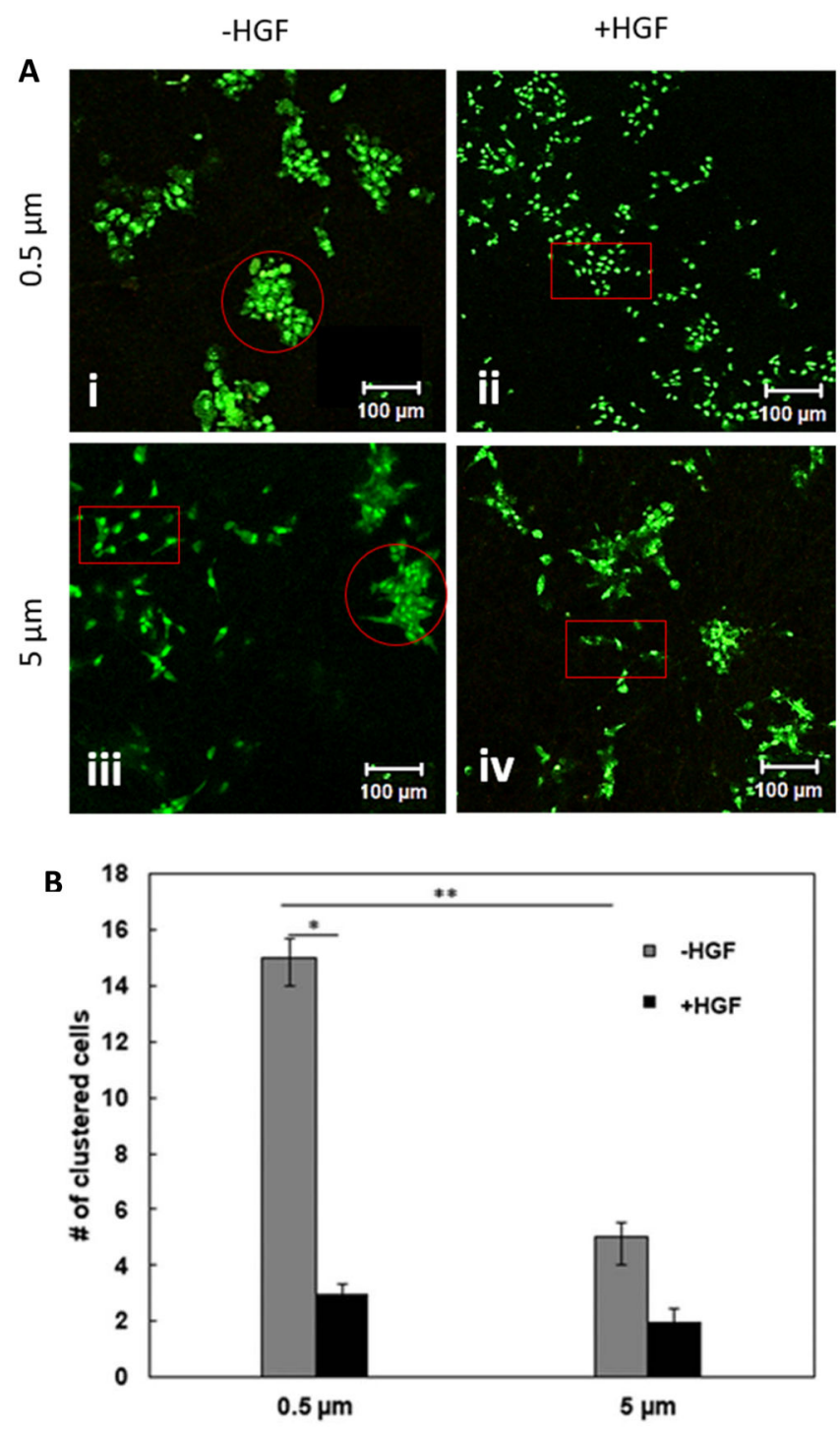

Fig. 5.

Characterization of cell clustering on small and large diameter fibers in the absence or presence of HGF by Live/Dead and confocal imaging. (A): Representative confocal images of MDCK cells stained by Syto 13 (live, green) and PI (dead, red). Circled areas represent clustered cells and boxed regions represent scattered cells. (B): Quantification of the number of clustered cells in both small and larger diameter scaffolds based on five separate 1,417 $\times$ $1,417 \mu \mathrm{m}^{2}$ confocal images. *Statistically ( $\mathrm{p}<0.05$, ANOVA) significant compared to HGFfree controls; $* *$ Statistically $(\mathrm{p}<0.05$, ANOVA) different between small and large diameter fibers. Error represents standard error of the mean from 3 repeats. 

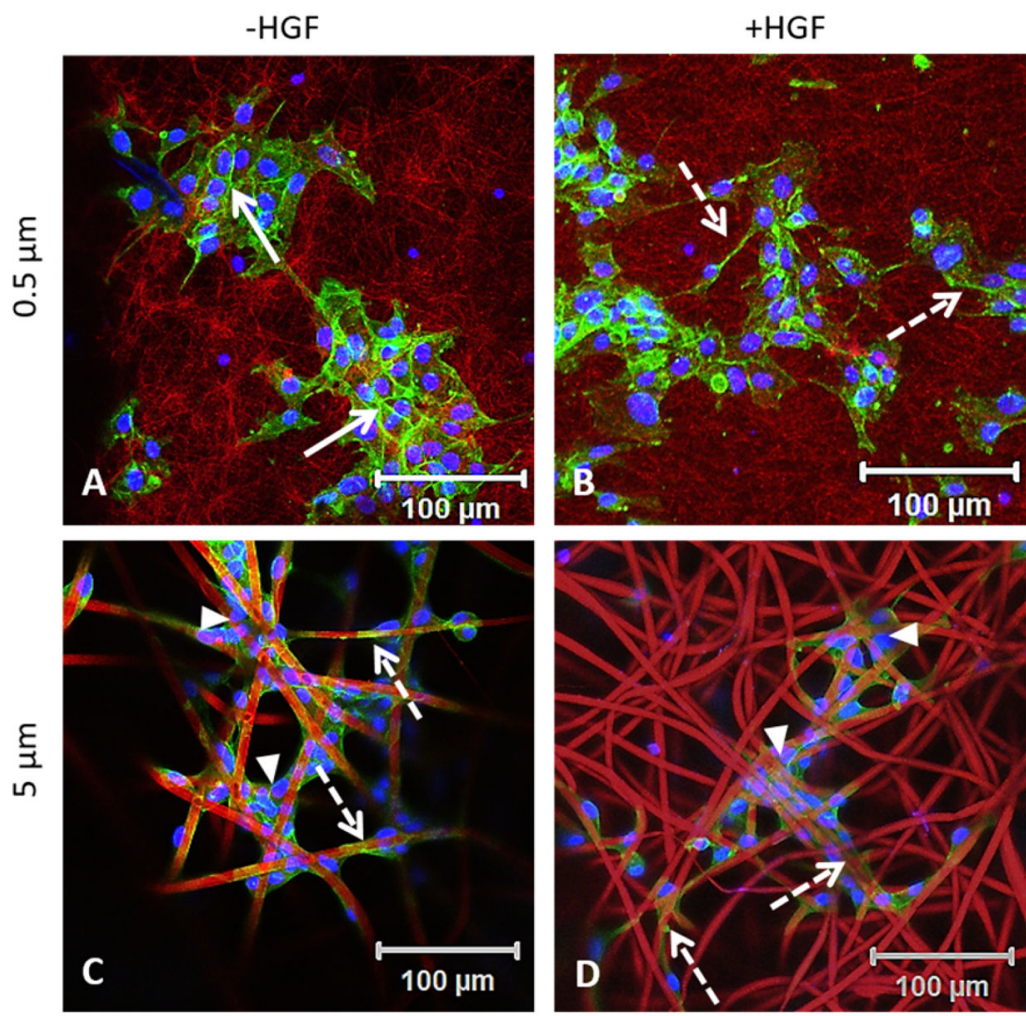

Fig. 6.

Fiber diameter affects the adhesion, spreading and scattering of MDCK cells. Cells cluster together, forming a cobble stone network in the absence of HGF on $0.5 \mu \mathrm{m}$ fibers (A). The addition of HGF induces MDCK cells to adopt a mesenchymal phenotype (B). Cells wrapped around $5 \mu \mathrm{m}$ fibers and adopted a spread out morphology in the absence (C) and presence (D) of HGF. Solid arrows indicate cell-cell junctions and dotted arrows point to Factin fibers. 


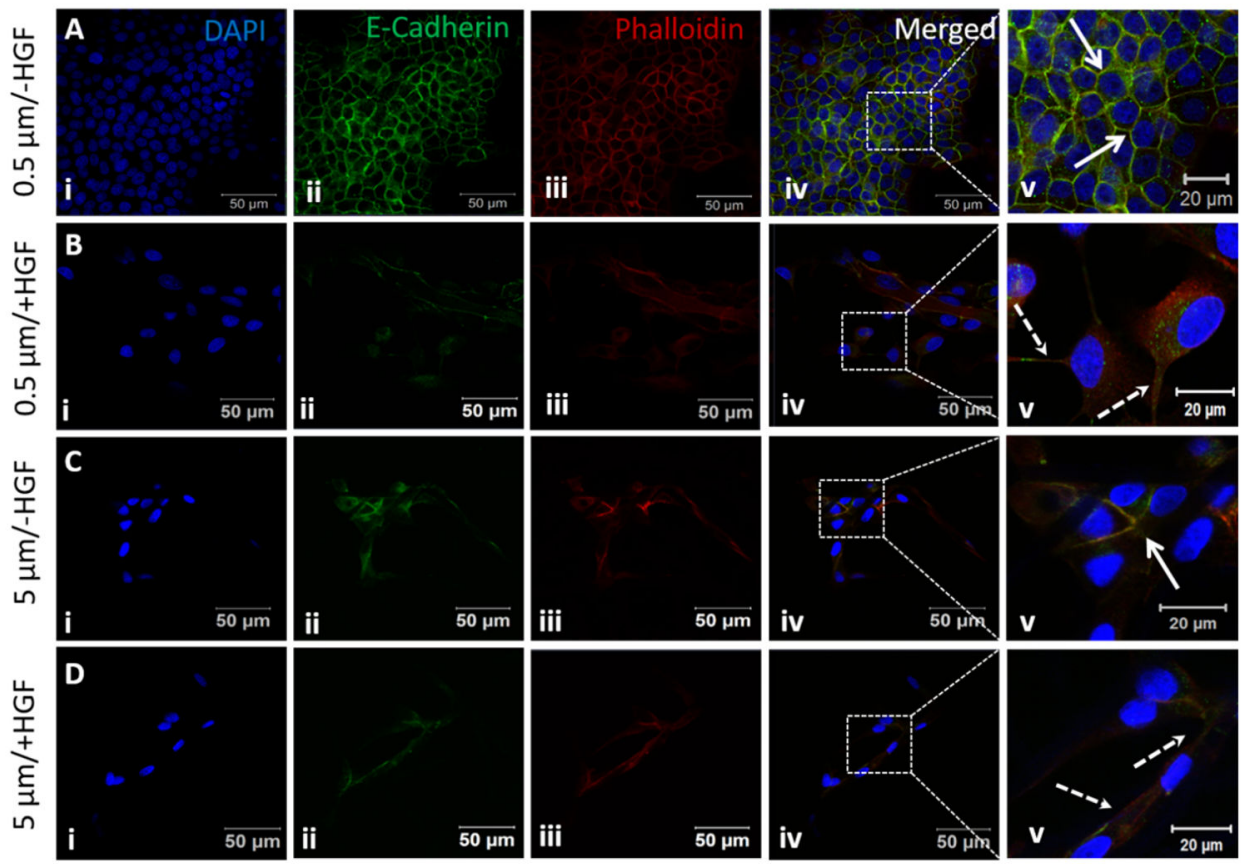

Fig. 7.

Expression of E-cadherin by MDCK cells cultured on small and large diameter fibers with or with HGF stimulation. Nuclei (i), E-cadherin (ii) and F-actin (iii) were stained blue, green and red, respectively. The boxed area in the merged image (iv) is shown at a higher magnification in v. Solid arrows indicate cell-cell junctions and dotted arrows indicate extended cell processes developed during EMT. 

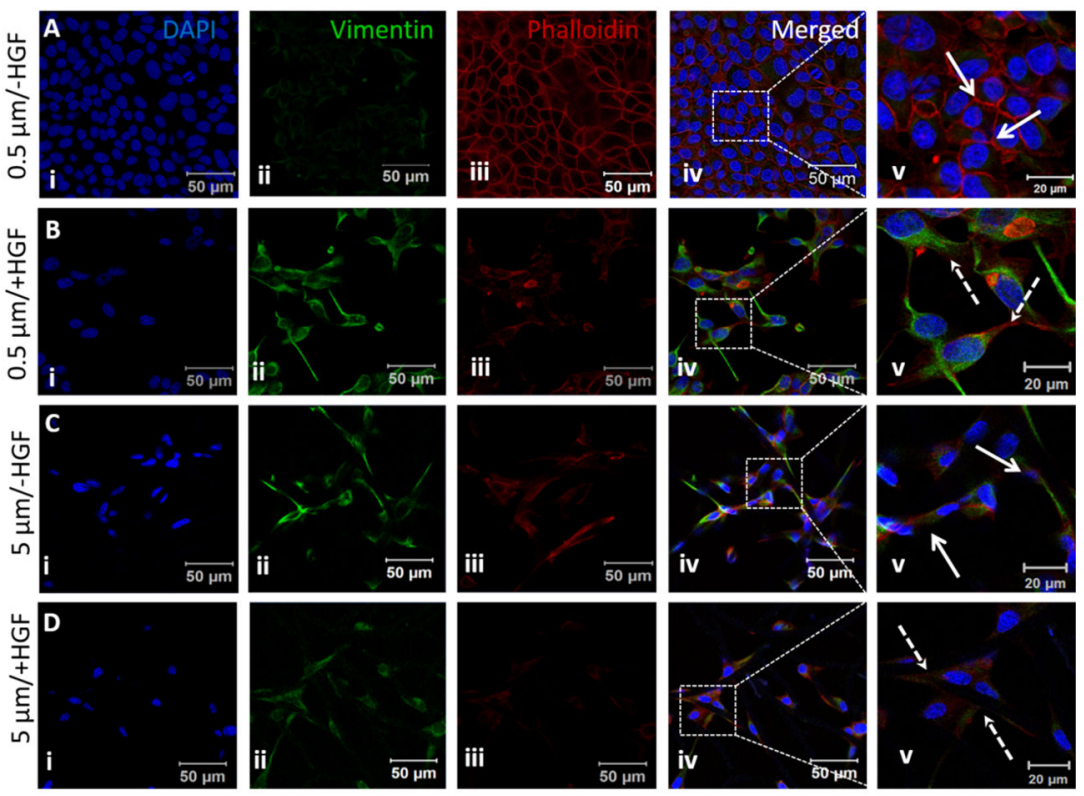

Fig. 8.

Expression of vinculin by MDCK cells cultured on small and large diameter fibers with or with HGF stimulation. Nuclei (i), vimentin (ii) and F-actin (iii) were stained blue, green and red, respectively. The boxed area in the merged image (iv) is shown at a higher magnification in v. Solid arrows indicate cell-cell junctions and dotted arrows indicate extended cell processes developed during EMT. 

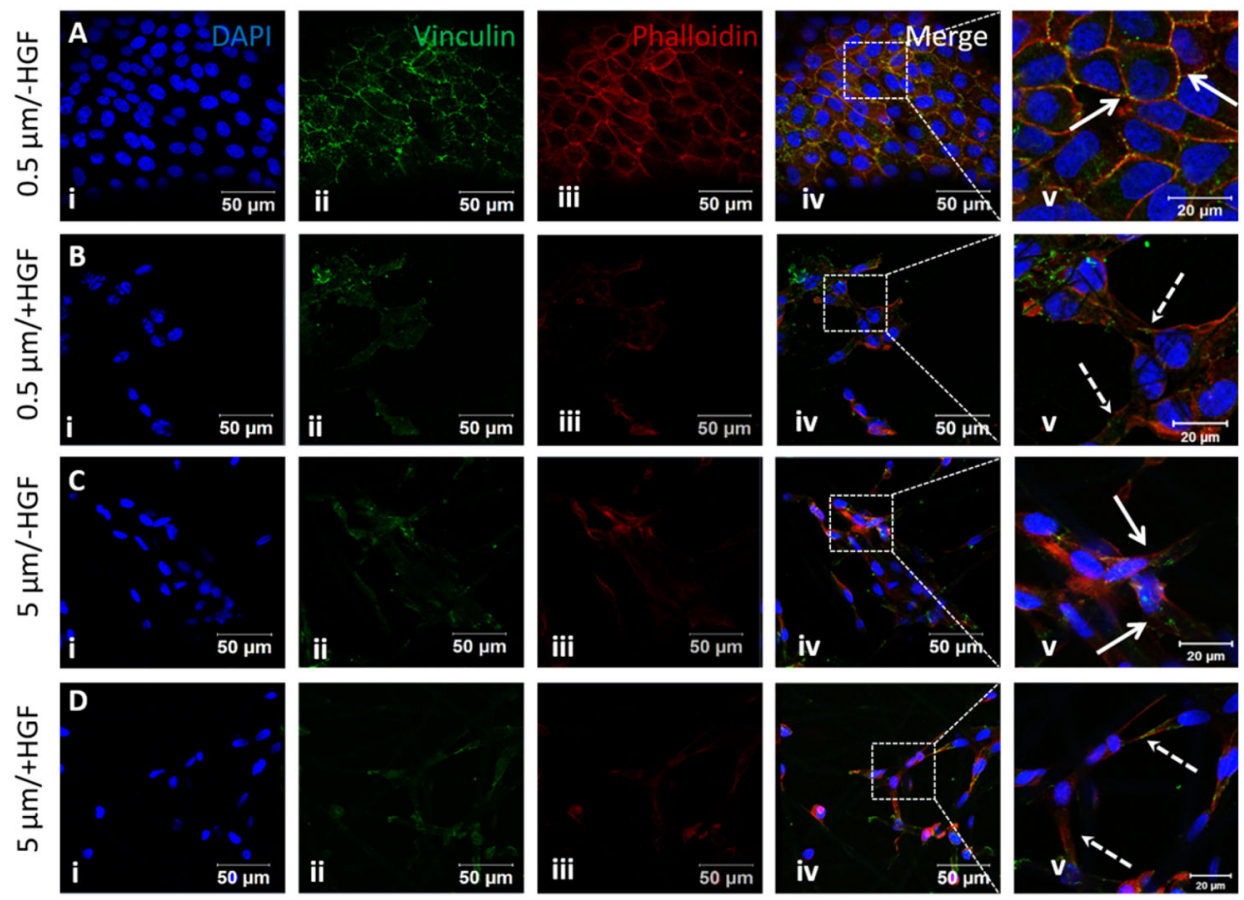

Fig. 9.

Expression of vinculin by MDCK cells cultured on small and large diameter fibers with or with HGF stimulation. Nuclei (i), vinculin (ii) and F-actin (iii) were stained blue, green and red, respectively. The boxed area in the merged image (iv) is shown at a higher magnification in v. Solid arrows indicate cell-cell junctions and dotted arrows indicate extended cell processes developed during EMT. 